\title{
Diferenciales socioespaciales de la mortalidad de los menores de cinco años en el Estado de México
}

\author{
José $B$. Morelos \\ El Colegio de México \\ Centro de Estudios Demográficos y \\ de Desarrollo Urbano \\ Camino al Ajusco No. 20 \\ Pedregal de Santa Teresa \\ 01000 México, D.F.
}

Tel. (5) 6454459

Fax (5) 6450464

Resumen

En el trabajo se presentan las estimaciones de la mortalidad infantil y de la niñez para el Estado de México según diversas características socioespaciales. Se amplía el análisis del contexto con la inclusión de tabulaciones especiales que combinan la escolaridad, la condición migratoria según lugar de nacimiento y la condición de actividad. Para estimar las tasas de mortalidad de los menores de cinco afios se eligieron los siguientes atributos de las madres: la escolaridad, la condición de actividad, el lugar de residencia, la condición migratoria según lugar de nacimiento y el estado civil. De los servicios dentro de la vivienda se seleccionaron dos variables: agua y drenaje.

Los datos sobre la migración y escolaridad indican que las migrantes cuentan con una mayor educación 
que las nativas, en particular las migrantes provenientes del DistritoFederal La concentración de la población migrante más escolarizada se localiza en los municipios conurbadosý el Área Metropolitanade Toluca y en las localidades de más de $15 \mathrm{mil}$ habitantes. La población menos escolarizada de las entidades restantes se concentra en los municipios conurbados. Respecto a la condición de actividad, los datos son consistentes con otros hallazgos en el sentido de que las mujeres activas tienen mayores niveles de estudios que las mujeres dedicadas a las labores del hogar.

En cuanto a los cálculos de la mortalidad en las primeras edades, se presentan los resultados para las variables seleccionadas en combinación con los siguientes arreglos territoriales: localidadescon menos de 15 mil y las de más, de 15 mil habitantes; municipios conurbados al Area Metropolitana de la Ciudad de México, Área Metropolitana de la Ciudad de Toluca y municipios no metropolitanos.

Los resultados indican que la variable de mayor influencia en el comportamiento de los indicadores seleccionados es la educación de la madre. Le siguen los servicios dentro de la vivienda y las categorías espaciales. Aunque los diferenciales son de poca monta, los resultados indican que los hijos de las madres que trabajan acusan menores riesgos de muerte que los vástagos de las que no trabajan. Patrón similar se observa con respecto a la variable migración menores riesgos para los hijos de las migrantes. Las diferencias más pequeñas se observan entre los hijos de madres unidas y solteras.

Al final se comparan algunos de los hallazgos del trabajo con los derivados de otros estudios.

\section{Introducción}

La finalidad de-este trabajo es analizar los patrones de comportamiento de la mortalidad infantil y de la niñez en el Estado de México hacia finales de la década de los ochenta. Al interés analítico de explicar los diferenciales de la mortalidad en las primeras

edades según diversas características socioespaciales, se debe añadir la preocupación por proporcionar elementos, cuantitativos y cualitativos, que puedan servir de orientación para el diseño y evaluación de las políticas y estrategias del sector salud tendientes a reducir las brechas existentes entre los diversos segmentos de la población mexiquense. Adicionalmente, se intenta hacer un uso més intensivo de la información contenida en la muestra de $1 \%$ del Censo General de Población y Vi vid de 1990, y así ainpliar el contenido del contexto sociodemográfico.

La disponibilidad de esta fuente de información permite hacer la estimación de los niveles de la mortalidad infantil y la de los menores de cinco años según disponibilidad de servicios - agua y drenaje - dentro de la vivienda; estado civil de las madres: unidas y solteras; por lugar de residencia de las madres: nativas y migrantes; condición de actividad: activas e inactivas; $y$, nivel de estudios: sin estudios, con 1 a 3 y de 4 a 6 años de primaria y con secundaria y más.

En primer lugar se examinan algunos planteamientos conceptuales que dicen del influjo de algunas variables en el comportamiento diferencial de la mortalidad de infantes y niños. El segundo apartado del estudio contiene algunas consideraciones sobre los arreglos espaciales utilizados, seguidas de una somera descripción de ciertas características de la población de 15 a 49 años en cada uno de estos entornos. La idea es ampliar el conocimiento del contexto con el examen de algunos datos inéditos relativos al nivel de estudios, migración según lugar de nacimiento $\mathbf{y}$ condiciones de actividad. En el siguiente apartado, se analizan y discuten los resultados de las estimaciones de la mortalidad infantil y de la niñez hacia 1988 obtenidas mediante el empleo de métodos indirectos tipo Brass'.

' En la estimación de los niveles de mortalidad se urilizó el paquete QPIVE (United Nations, 1990). Lar resultados que se presentan provienen de la aplicaciónde la variante de Trussell, que utiliza las tablas modelos de Coale y Demeny. De éstas se elegió el Modelo Oeste. No se incluyen los resultados obtenidos conla variante Heligman-Palloni, autores que emplean las tablas de Naciones Unidas de las cuales se seleccionó la tabla modelo de Latinoamérica.

Los resultados se refieren al grupo de edades 20-24, por lo que las estimaciones que lar datos estimados corresponden a fecthas distintas se ha adoptado, por mones prícticas, el término "hacia 1988". 
PRIMERA PARTE

RESUMEN DE LOS PRINCIPALES HALLAZGOS

Un resumen de los elementos sustantivos de algunas propuestas analíticas para el estudio de la mortalidad en las primeras edades se encuentra en Aguirre et al. (1995) y Morelos (1996). En los mismos se hace un breve repaso de algunas de las principales hipótesis y se resumen los hallazgos de varios estudios relativos al comportamiento de la mortalidad en las primeras edades según la escolaridad de la madre, residencia urbano rural y servicios dentro de la vivienda ${ }^{2}$.

De manera sistemática, los resultados provenientes de estudios en los que la unidad de análisis seleccionada ha sido la familia, la unidad doméstica o bien las características de la madre, documentan la existencia de diferenciales de la mortalidad en las primeras edades según clase social o grupos sociales seleccionados (campesino, obrero y marginal urbano). Muestran de forma clara la presencia de variaciones en los valores de las tasas de mortalidad según la edad de la madre al tener sus hijos, la edad al casarse, duración de los intervalos intergenésicos, calidad de los servicios dentro de la vivienda, lugar de residencia y tipo de ocupación de las madres. Dichas investigaciones aportan elementos suficientes para concluir que la tendencia a repetir muertes infantiles es más acentuada entre las estructuras familiares con mayor grado de disfuncionalidad y de rigidez. También confirman la importancia que tienen las redes sociales, en especial para las madres que

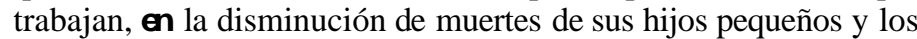
vínculos existentes entre los tipos de familia, la migración y la morbilidad de los menores. La peculiaridad de este conjunto de estudios está relacionada con el rol de la escolaridad de la madre en el comportamiento de la mortalidad en los primeros años. Ya sea que se utilicen las clases sociales, la unidad doméstica, los tipos de familia o las características de la madre, se encuentra una y otra vez que del conjunto de variables sociales, la más importante es la educación de la madre, y en todos los casos ha resultado estadísticamente significativa (Aguirre, Morelos y Pimienta, 1995;

2 Los datos mencionados por Morelos (1996) provienen de la Encuesta Nacional de Prevalencia en el Uso de Métodos Anticonceptivos con Módulo Fecundidad/Mortalidad, 1980 (García España y Mojarro, 1982); Encuesta Nacional Demogrífica, 1982 (Bronfman y Tuirán. 1984); Encuesta Mexicana de Fecundidad, 1976 (Gómez de León, 1988); y las encuestas en distintos contextos del proyecto Mortalidad Infatil y Grupos Sociales Giménez $O$. y Menuiin. 1982).
Bronfman, 1990, 1994; Bronfman y Tuirán, 1984; Camposortega, 1992; Echarri, 1995; García España y Mojarro Dávila, 1982; García y Garma, 1983; Gómez de León, 1988; Hobcraft, McDonald y Rutstein, 1984; Holian, 1989; Jiménez Ornelas, 1988,1993; Jiménez Ornelas y Menujin, 1982; Menujin et al., 1984; Martínez, 1992,1994; Medina, 1994; Mina, 1981; Mojarro y Aznar, 1986; Mojarro y Nuñez, 1988; Nuñez, 1992; Ordorica Mellado, 1982; Romero Montilla, 1994)

De los trabajos consultados resulta evidente el poco tratamiento que ha recibido el binomio compuesto por la mortalidad infantil y la migración interna o internacional. En los pocos trabajos disponibles, el análisis de ambas variables se diseña para las mujeres que han tenido al menos un hijo fallecido; el grado de riesgo para las madres con al menos un hijo vivo, y para asociar a la migración, entre otras variables, con la presencia en el hogar de un enfermo entre sus miembros o integrantes. En dos de los trabajos (Bronfman y Tuirán, 1984; Menujin et al., 1984) los comentarios dejan de lado el examen de influencia mayor o menor de la migración sobre la salud de los hijos. Pero de la lectura del arreglo bivariado en el que se utiliza el tipo de riesgo como variable dependiente presentado por Bronfman y Tuirán (1984), se infiere que la proporción de mujeres de riesgo bajo disminuye en el caso de ser mujeres migrantes y también para las migrantes rurales-rurales. Es decir, los hijos de mujeres migrantes y de las migrantes de origen y destino rurales tiene condiciones de salud más adversas que los hijos de las no migrantes y los de aquellas que emigran de y hacia áreas urbanas. Del conjunto de datos presentados por dichos autores las diferencias porcentuales más bajas son las correspondientes a la condición migratoria y al tipo de migración ${ }^{3}$. Otro de los autores que han explorado los nexos entre la migración temporal y la morbilidad, mas no la mortalidad, encuentra que la presencia de un enfermo entre los moradores de las unidades domésticas se asocia, entre otros factores, con la migración temporal (Martínez, 1992). Para el caso concreto de los niños de las comunidades mexiquenses estudiadas, la autora señala "y los niños de unidades que no recurren a la migración mostraron más elevados niveles de morbilidad que los de aquellas que sí utilizan este recurso [...]" (Martínez, 1994, p. 216).

3 En el arreglo bivariado en donde el tipo de riesgoes la variabledependiente, los factores explicativos de mayor peso son: el nivel de escolaridadde la madre, la edad de la misma al dar a luz al primer hiio $v$ la clase social (véase Bronfman $v$ Tuirán 1984 ruadrn 4) 
Un estudio reciente cuyos resultados provienen de tres comunidades potosinas, examina los nexos entre la migración hacia Estados Unidos y la salud de los hijos. Se plantea como hipótesis que la migración influye de manera directa sobre los determinantes próximos, e indirectamente mediante la modificación del estatus socioeconómico de los hogares como resultado de los ingresos de retorno. La disponibilidad de mayores recursos monetarios influye en los niveles nutricionales y en el acceso y uso de los servicios de salud; factores que explican la menor mortalidad entre los hijos pertenecientes a los hogares productores de migrantes hacia Estados Unidos (Kanaiaupuni y Donato, 1995) ${ }^{4}$.

Respecto a la condición de actividad los resultados son ambiguos. Cuando se estiman los diferenciales con base en las tasas de mortalidad infantil los hallazgos indican que los riesgos de muerte para los hijos de las mujeres que trabajan son mayores que los de los vástagos de las mujeres dedicadas a las labores del hogar. Con la salvedad de que este comportamiento se observa sólo a nivel nacional y en las localidades rurales (García España y Mojarro, 1982; Morelos etal., 19\%; Núñez, 1992). Pero en la región fronteriza y en las áreas urbanas y metropolitanas, las mujeres activas registran tasas de mortalidad en los menares de tres años inferioresa las de aquellas que no trabajan (García España y Mojarro, 1982; Nuñez, 1992). Una relación inversa surge cuando se estiman los diferenciales según el tipo de riesgo. La proporción de mujeres que siempre han trabajado y que presentan un riesgo bajo es casi 15 por ciento superior a la de mujeres que nunca han trabajado (Bronfman y Tuirán, 1984).

A partir de los hallazgos reseñados es posible proponer cuando menos dos supuestos operacionales. El primera plantea que los diferenciales de mayor magnitud deberán corresponder a la educación y servicios dentro de la vivienda; los de menor cuantía a la condición de actividad y migración según el lugar de nacimiento. La segunda hipótesis consta de dos apartados: a) los cambios más importantes en los niveles de las tasas de mortalidad infantil y de la

4 En un trabajo reciente se estudian las interacciones entre el cido de vida de la familia y la migración a las áreas metropolitanas (Juirez, 1996). Dicha investigación se centra sólo en la nupcialidad y fecundidad. Aunque deja de lado la mortalidad, algunas de sus hipótesis podrían ser replanteadas para el caso de esta última variable. En esta perspectiva resultaría de interés analizar el efecto que tiene el cambio en los patrones de fecundidad sobre la mortalidad infartil de las madres según $m$ cóndición migratoria. Pero pan establecer la dirección e importancia del efecto se requiere disponer, además de las historias de migración, de las relativas a la salud de los miembros de los hogares o familias, datos que no fueron captados. niñez se dan entre las mujeres sin estudios y aquellas que cuentan con 1 a 3 años de primaria, y b) las mujeres más escolarizadas (con secundaria y más) y que tengan por residencia los municipios de corte metropolitano mostrarán diferencias menores que sus similares de los municipios no metropolitanos. En este sentido, es dable esperar que los valores de las tasas de mortalidad infantil y de la niñez entre las madres con secundaria y más sean muy similares en los ámbitos urbano y metropolitano. Dicho de manera distinta, para las madres escolarizadas residentes en estos espacios territoriales la producción de salud de sus hijos se encuentra en una fase de rendimientos decrecientes.

\section{SEGUNDA PARTE}

LAS CATEGORÍAS ESPACIALES

Como se mencionó al inicio del trabajo, la finalidad de este apartado es hacer un breve análisis de datos inéditos acerca de algunas características sociodemográficas de la población en edades 15-49. Para ello se han tomado distintas unidades territoriales, las cuales han sido delimitadas y empleadas en otros estudios (Aguado López, 1994, 1995; Graizbord y Mina, 1994; Hernández, 1995; Negrete, 1995; Rodríguez, 1994; Sobrino, 1994a, 1994b).

Para los fines del trabajo la población del estado se subdivide en a) habitantes de los municipios conurbados que forman parte del área metropolitana de la ciudad de México (AMCM); b) los del área metropolitana de la ciudad de Toluca (AMCT); y, c) los moradores en el resto de lo municipios, designados como "no metropolitanos". Para determinar el universo de municipios conurbados se eligió la delimitación hecha por Negrete (1995) y para el AMCT la de Sobrino (1994a). Para cada una de estas categorías de municipios se establece la subdivisión: localidades con menos de 15 mil habitantes (rurales), y las que cuentan con más de 15 mil personas (urbanos) ${ }^{5}$.

S En el texto se designará como municipios metropolitanos al conjunto formado por loa municipios conurbados y la, del AMCT. Por otra parte, en la mayoría de loa estudios que tratan $e l$ tema de los diferenciales de la mortalidad infantil se utiliza la definición de localidades urbanas como aquellas que tienen una población superior a los 20 mil habitantes. En nuestro caso el criterio más afín a tal concepto e $n$ el de 15 mil habitantes, ya que en la muestra los datos se agrupan en localidades de menos de 2,500; de 2,500 a 14,999; de 15,000 a 99,999; de 100,000 a 499,999, y de 500,000 y más. 
Perfil sociodemográfico

El monto de la población total en $\mathbf{1 9 9 0}$ de la muestra de $\mathbf{1 \%}$ era de 97,765 habitantes. En ese año los asentamientos humanos en los municipiosconurbados concentraban $\mathbf{7 0 . 8}$ por ciento de la población estatal, en la AMCT su porcentaje era de 9.1 y en los municipios no metropolitanos residía el $\mathbf{2 0 . 1}$ por ciento restante. De los $\mathbf{9 . 8}$ millones de habitantes del Estado de México, 51 por ciento corresponde a la población femenina. Las mujeres entre los 15-49 años representan $\mathbf{8 5 . 3}$ por ciento de las $\mathbf{2 . 3}$ millones de mujeres de 15 años y más.

Estado civil de la población femenina de 15-49

Como se aprecia en el cuadro 1 , la categoría unidas ${ }^{6}$ entre 15-49 años presenta, en todos los casos, los valores más altos en el grupo de edad 25-39. Los porcentajes de las localidades urbanas superan a los estimados para las rurales. Por otra parte, la distribución de las mujeres célibes según los grupos de edad considerados observa una disminución importante en los porcentajes al pasar de los grupos de edades jóvenes a los subsecuentes.

Tanto los niveles de los valores correspondientes a la categoría de unidas como a la de solteras indican mayor frecuencia de matrimonios entre la población femenina de 15-24 años. La proporción de mujeres "unidas" respecto a la población total es mayor en los municipios no metropolitanos y en las localidades rurales. Por ejemplo, en los municipios conurbados que cuentan con localidades cuya población total es inferior a los $\mathbf{1 5}$ mil habitantes, el valor de dicha proporción es de $\mathbf{4 0 . 9}$ por ciento. En las localidades de igual tamaño pertenecientes a la categoría de no metropolitanos el valor sube a $\mathbf{4 4 . 4}$ por ciento. En cambio, en los municipios conurbados y localidades urbanas el porcentaje de mujeres unidas baja a 33.0 y el correspondiente a los no metropolitanos y ámbitos urbanos es de $\mathbf{4 0 . 6}$ por ciento. Por la escasa importancia que tienen en este grupo de edad las mujeres con uniones desechas se puede decir que el comportamiento diferencial de estos porcentajes es un indicio de que el ingreso a las uniones se da a edades más tempranas

'Esta categoría incluye a la población casada según las diferentes modalidades (civil, religioso, civil y religioso, unión consensual), a las separadas, divorciadas y viudas. en los municipios no metropolitanos y localidades rurales (véase cuadro 1).

\section{Niveles de estudios de la población femenina de 15-49}

Las cifras absolutas y relativas de la población total según el nivel de estudios se incluyen en el cuadro 2. Si se comparan los porcentajes de la columna "total" correspondientes a los municipios conurbados y al AMCT se observan diferencias pequeñas; las discrepancias afloran al confrontarse los valores de los municipios metropolitanos con los de corte no metropolitano. Estos últimos se encuentran en una situación de relativa desventaja: la proporción de poblaçión sin estudios, $\mathbf{1 5 . 4} \%$, es casi tres veces superior a la de los conurbados y un poco más del doble de los que conforman la AMCT, y la mayor concentración de la población en estas edades se tiene en el nivel primaria.

Con base en los datos de dicho cuadro se podría suponer que os habitantes mexiquenses de un municipio de corte metropolitano con población viviendo en localidades con más de $\mathbf{1 5}$ mil habitantes cuehtan con un factor locacional que aumenta sus oportunidades para acceder a un nivel superior de estudios. En contraste, todas aquellas personas que radican en un municipio no metropolitano y en localidades rurales se ven excluidas de dicha ventaja. Hay que subrayar que desde un punto de vista més amplio, las diferencias de oportunidades según el tipo de municipios se explica por factores de oferta y de demanda tales como la distribución de la infraestructura educativa entre los tres distintos tipos de municipios aquí considerados, el grado de acceso a los distintos niveles del ciclo escolar, el tamaño de las familias y el nivel del ingreso familiar. En consecuencia, la posibilidad de acceder al sistema educativo de nivel medio y medio superior será menor para la gente de los sectores de menores recursos y que residen en localidades rurales.

Este comentario es respaldado por los resultados derivados del examen de las igualdades en el acceso a la educación en el Estado de México. Dichos hallazgos muestran que tanto el carácter ruralurbano o metropolitano de los municipios como su grado de marginación son factores que influyen en la desigualdad en el acceso al sistema educativo formal y en su grado de cobertura (Aguado, 1994). 
Cuadro 1

Estado de México: Poblacion femenina por estado civil, edad, residencia metropolitana y rural-urbana, 1990 (cifras relativas)

\begin{tabular}{|c|c|c|c|c|}
\hline \multirow{2}{*}{$\begin{array}{l}\text { Municipios } \\
\text { conurbados }\end{array}$} & \multicolumn{2}{|c|}{ Menos de 15000} & \multirow{2}{*}{\multicolumn{2}{|c|}{$15000 y$ más }} \\
\hline & thidas" $^{*}$ & Soltenas & & \\
\hline $15-24$ & 24.09 & 80.89 & 20.72 & 79.69 \\
\hline $25-39$ & 54.48 & 16.38 & 58.31 & 17.57 \\
\hline $40-49$ & 21.43 & 2.73 & 20.97 & 2.74 \\
\hline Towl & 100.00 & 100.00 & 100.00 & 100.00 \\
\hline ZMCT & & & & \\
\hline $15-24$ & 25.04 & 88.57 & 17.73 & 75.97 \\
\hline $25-39$ & 56.44 & 8.16 & 61.51 & 21.21 \\
\hline $40-49$ & 18.52 & 3.27 & 20.76 & 2.82 \\
\hline & 100.00 & 100.00 & 100.00 & 100.00 \\
\hline $\begin{array}{l}\text { No Metrop. } \\
15-24\end{array}$ & 25.56 & 84.76 & 22.62 & 78.49 \\
\hline $25-39$ & 52.51 & 12.05 & 54.75 & 17.21 \\
\hline $40-49$ & 21.93 & 3.18 & 22.63 & 4.3 \\
\hline Total & 100.00 & 100.00 & 100.00 & 100.00 \\
\hline
\end{tabular}

ans, unidas, septrides, divorchd

Fuente: Elaboraciones del autor.

Cuadro 2

Estado de México: Poblacion 15-49 años por nivel de estudios, lugar de residencia y tipo de municipios, 1990

\begin{tabular}{|c|c|c|c|c|c|}
\hline Estudios & \multicolumn{5}{|c|}{ Municipios comurbados } \\
\hline & $15000 y+$ & $\%$ & -15000 & $\%$ & Tobat \\
\hline Siri estudios & 1776 & 5.16 & 231 & 8.07 & 5.38 \\
\hline Primaria & 12417 & 36.07 & 127 & 44.67 & 36.73 \\
\hline Secundaria & 12080 & 35.09 & 964 & 33.72 & 34.98 \\
\hline Prepa. y+ & 8153 & 23.68 & 387 & 13.54 & 22.91 \\
\hline Toal & 34426 & 100.00 & 2859 & 100.00 & 100.00 \\
\hline Sin escudios & 124 & 4.47 & 210 & 11.53 & 7.28 \\
\hline Primaria & 737 & 26.61 & 904 & 49.64 & 35.74 \\
\hline Secundaria & 1014 & 36.61 & 520 & 28.56 & 33.41 \\
\hline & 895 & 32.31 & 187 & 10.27 & 23.57 \\
\hline \multirow{2}{*}{ Total } & 2770 & 100.00 & 1821 & 100.00 & 100.00 \\
\hline & \multicolumn{5}{|c|}{ Municipios no metropolimas } \\
\hline Sin estudios & 43 & 6.65 & 1307 & 16.06 & 15.36 \\
\hline Primaria & 244 & 37.71 & 4309 & 52.92 & 51.80 \\
\hline Secundaria & 235 & 36.32 & 1847 & 22.68 & 23.69 \\
\hline Prepa.y + & 125 & 19.32 & 679 & 8.34 & 9.15 \\
\hline & 647 & 100.00 & 8142 & 100.00 & 100.00 \\
\hline
\end{tabular}

Fuente: Elbboractones del autor.
Población de 15-49 años según el lugar de nacimiento y el nivel de estudios

A la par de factores locacionales y socioeconómicos, la migración se considera también como un elemento que puede influir en el grado de escolaridad de la población (Aguado, 1994)'.

En los cuadros 3, 4 y 5 se presentan tabulaciones que relacionan el nivel de estudios de la población nativa y migrante, clasificada esta última en: a) nacidos en el Distrito Federal, y b) nacidos en otra entidad y en el extranjero (véase cuadros 3,4 y 5). La comparación de los cuadros 3 y 4 ilustra las diferencias existentes entre las poblaciones nativa y la migrante oriunda del Distrito Federal. Los datos indican de forma sistemática que el analfabetismo es menor entre los migrantes procedentes del Distrito Federal y que han fijado su residencia en los municipios conurbados, en el área metropolitana de la ciudad de Toluca o bien en los no metropolitanos. Un segundo aspecto es que la mayor proporción de población sin estudios se localiza en los municipios no metropolitanos sin importar el tamaño de la localidad (urbana o rural). Otro rasgo es que la proporción de población nacida en el Distrito Federal con estudios de secundaria y más favorece a los municipios conurbados y localidades de corte urbano y a los del AMCT

Por lo que respecta a la población migrante de otras entidades ${ }^{8}$, aquellos sin estudios se concentran mayoritariamente en los municipios conurbados y no metropolitanos. En estos mimos espacios geográficos se concentra también la población con nivel primaria incompleta y completa.

La distribución relativa de la población migrante de otras entidades en el AMCT indica que el porcentaje de educación con secundaria y más supera con más de 30 puntos al de los municipios

' El autor hace mención sobre la ssociación entre los índices de atención y la condición migratoria. Con base en su comentario se desprende que el papel de la migración es un tanto ambiguo. En las regiones de alta atracción como en las de fuerte rechazo el promedio de atención fluctúz entre 40 y $46 \%$ y en las de atracción media y las de rechazo el porcentaje es casi igual, 54.3 y 55.2 respectivamente (véase Aguado, 1994, nota 6, p.568).

No hay duda de que seria de intés establecerlos efectos dirctos o indirectos de a migración tanto en los lugares de destino como en los de origen sobre el ando de a riga indicador, pero esta tarea rebasa los p

${ }^{8}$ En este grupo están incluidos los migrantes de las 30 entidades federativas restantes y los 
Cuadro 3

Estado de México: Población de 15-49 por lugar de nacimiento, nivel de estudios, urbano-rural y tipo de municipios, 1990 (cifras absolutas y relativas)

\begin{tabular}{|c|c|c|c|c|c|}
\hline \multirow{2}{*}{ Estiudias } & \multicolumn{5}{|c|}{$\begin{array}{l}\text { Nativos del Estado de Mexio que viven en } \\
\text { Municipios conurbados }\end{array}$} \\
\hline & $15000 y+$ & $\%$ & -15000 & 96 & Total \\
\hline Sin esaudios & 549 & 4.54 & 170 & 7.56 & 5.01 \\
\hline Primaria & 4061 & 33.54 & 1008 & 44.84 & 35.31 \\
\hline secundaria & 4872 & 40.24 & ni & 34.9 & 39.31 \\
\hline Prepa. y* & 2625 & 21.68 & 299 & 13.9 & 20.37 \\
\hline \multirow[t]{2}{*}{ Total } & \multirow{2}{*}{\multicolumn{5}{|c|}{ Municipios de la ZMCT }} \\
\hline & & & & & \\
\hline Sin estudios & 109 & 5.02 & 200 & 11.61 & 7.94 \\
\hline $\begin{array}{l}\text { Primaria } \\
\text { Pas }\end{array}$ & 617 & 28.42 & 864 & 50.14 & 38.03 \\
\hline Secundaria & 845 & 38.92 & 489 & 28.38 & 34.26 \\
\hline \multirow{3}{*}{$\begin{array}{l}\text { Prepa. Y + } \\
\text { Total }\end{array}$} & 600 & 27.64 & 170 & 9.87 & 19.77 \\
\hline & 2171 & 100.00 & 1723 & 100.00 & 100.00 \\
\hline & \multicolumn{5}{|c|}{ Municipios no metropolitanos } \\
\hline Sin estudios & 37 & 6.39 & 1256 & 4.51 & 15.91 \\
\hline Primaria & 215 & 3750 & 4061 & 28.95 & 23.24 \\
\hline Secundaria & 221 & 25.00 & 1667 & 40.60 & 52.61 \\
\hline Prepa. $Y_{+}$ & 106 & 33.33 & 564 & 25.94 & 8.24 \\
\hline Total & 579 & 10000 & 7548 & 100.00 & 100.00 \\
\hline
\end{tabular}

Fuente Elaboractones del autor

\section{Cuadro 4}

Estado de México: Población de 15-49 por lugar de nacimiento, nivel de estudios, urbano-rural y tipo de municipios, 1990 (cifras absolutas y relativas)

\begin{tabular}{|c|c|c|c|c|c|}
\hline \multirow[t]{2}{*}{ Estudios } & \multicolumn{5}{|c|}{ 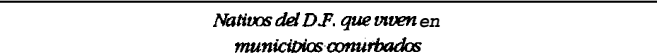 } \\
\hline & $15000 y+$ & & & 96 & \\
\hline Sir esudios & $\begin{array}{r}3000+ \\
169\end{array}$ & 1.50 & 6 & 2.34 & 1.53 \\
\hline Primaria & 2587 & 23.02 & 76 & 29.57 & 23.16 \\
\hline Secundaria & 4547 & 40.46 & 118 & 45.91 & 40.58 \\
\hline Prepa Y+ & 3936 & 35.02 & 57 & 22.18 & 34.73 \\
\hline \multirow[t]{2}{*}{ Tobal } & 11239 & $\begin{array}{r}53.02 \\
100.00 \\
\end{array}$ & 257 & $\begin{array}{r}22.10 \\
100.00\end{array}$ & $\begin{array}{r}54.15 \\
100.00\end{array}$ \\
\hline & \multicolumn{5}{|c|}{ Municipios de la ZMCT } \\
\hline Sin estudios & 5 & 2.43 & 1 & 244 & 244 \\
\hline Primaria & 32 & 15.53 & 12 & 29.27 & 17.81 \\
\hline Secundaria & 63 & 30.58 & 20 & 48.78 & 33.60 \\
\hline $\begin{array}{l}\text { Pecuncana } \\
\text { Prepa y }\end{array}$ & 106 & 51.46 & 8 & 1951 & 46.15 \\
\hline \multirow[t]{2}{*}{ Total } & 206 & 100.00 & 41 & 100.00 & 100.00 \\
\hline & \multicolumn{5}{|c|}{ Municipios no metropolitanos } \\
\hline Sin estudios & 1 & 4.17 & 11 & 4.55 & 4.51 \\
\hline Primaria & 9 & 37.50 & 68 & 28.10 & 28.95 \\
\hline Secundaria & 6 & 25.00 & 102 & 4215 & 40.60 \\
\hline Prepa. $Y^{+}$ & 8 & 33.33 & 61 & 25.21 & 25.94 \\
\hline Tatal & 24 & 100.00 & 242 & 100.00 & 100.00 \\
\hline
\end{tabular}

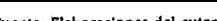

Cuadro 5

Estado de México: Población de 15-49 por lugar de nacimiento, nivel de estudios, urbano-rural y tipo de municipios, 1990 (cifras absolutas $\boldsymbol{y}$ relativas)

\begin{tabular}{|c|c|c|c|c|c|}
\hline \multirow[t]{2}{*}{ Estudios } & \multicolumn{5}{|c|}{$\begin{array}{l}\text { Naticos de otros stados que viven en } \\
\text { munictpios conurbados }\end{array}$} \\
\hline & $15000 y_{+}$ & $\$$ & -15000 & $\begin{array}{lll}\% \\
\%\end{array}$ & Total \\
\hline sin estudios & & & & 1553 & \\
\hline Primaria & 5769 & 52.07 & 193 & 54.52 & 52.14 \\
\hline Secundaria & 2661 & 24.02 & 75 & 21.19 & 23.93 \\
\hline Prepa. y+ & 1592 & 14.37 & 31 & 8.76 & 14.19 \\
\hline Total & \multicolumn{5}{|c|}{ Municipios de la ZMCT } \\
\hline Sin estudios & 10 & 254 & 9 & 15.79 & 4.22 \\
\hline Primaria & 88 & 22.39 & 28 & 49.12 & 25.78 \\
\hline Secoundaria & 106 & 26.97 & 11 & 19.30 & 26.00 \\
\hline \multirow{2}{*}{ Towal } & 189 & 48,09 & 9 & 15.79 & 44,00 \\
\hline & \multicolumn{5}{|c|}{ Municipios no metropolitanos } \\
\hline Sin estudios & 5 & 11.36 & 40 & 11.36 & 11.36 \\
\hline Primaria & 20 & 45.45 & 180 & 51.14 & 50.51 \\
\hline Secundaria & 8 & 18.18 & 78 & 22.16 & 21.72 \\
\hline Prepa.y + & 11 & 25.00 & 54 & 15.34 & 16.41 \\
\hline Tomal & 44 & 100.00 & 352 & 100.00 & 100.00 \\
\hline
\end{tabular}

Cuadro 6

Estado de México: Índices de disimilaridad de los niveles de escolaridad de la población

según lugar de nacimiento, 1990

\begin{tabular}{|c|c|c|c|}
\hline \multicolumn{4}{|c|}{ Nativos del Estado de México residiendo en*: } \\
\hline Municipios & Conurb. & ZMCT & No met. \\
\hline - de 15000 & 11.9 & 11.9 & 29.9 \\
\hline $15000 y+$ & 5.0 & 5.4 & 5.9 \\
\hline \multicolumn{4}{|c|}{ Nativos del Distrito Federal residiendo en ${ }^{*}$; } \\
\hline - de 15000 & 20.4 & 30.0 & 37.8 \\
\hline $15000 y+$ & 15.6 & 23.8 & 15.4 \\
\hline \multicolumn{4}{|c|}{ Nativos de Otros estados residiendoen*: } \\
\hline - de 15000 & 17.7 & 10.1 & 7.9 \\
\hline $15000 y+$ & 23.5 & 20.5 & 20.0 \\
\hline
\end{tabular}


restantes, y se acerca al valor que registran los migrantes procedentes del Distrito Federal (véase cuadro 6). En este cuadro se presenta un índice-resumen que mide lo disímil de las distribuciones según los niveles de estudios de la población nativa y migrante. Cuando los valores de este indicador se aproximan a cero, las distribuciones que se comparan resultan casi semejantes; en el caso contrario se presentan marcadas diferencias 9 . El comportamiento de los valores del citado índice confirman los comentarios vertidos con anterioridad.

Varias observaciones se desprenden de los cuadros citados: a) el volumen de migrantes nacidos en los 30 estados restantes, 1.2 millones, supera en 272 mil al total de los migrantes provenientes del Distrito Federal; $b$ ) un poco más de $\mathbf{9 4 \%}$ del volumen total de migrantes en el Estado de México se concentra en los municipios conurbados, los 134 mil restantes se distribuyen por igual entre el AMCT y los no metropolitanos; c) los datos sugieren que los migrantes que proceden del Distrito Federal son los más escolarizados, hecho que se desprende cuando se compara su perfil con los correspondientes a la población migrante de las otras entidades y al de la población nativa; y, d) según los perfiles educativos, la población nativa residente en las localidades con población menor a los 15 mil habitantes es la menor escolarizada de la entidad.

Las diferencias que se observan para la población nativa entre localidades urbanas y rurales pueden ser el reflejo de las desigualdades educativas atribuidas tanto a factores de localización de los servicios educativos, como a los de índole económica y social (Aguado, 1995). La concentración de los migrantes con secundaria y más nacidos en el Distrito Federal y en otras entidades se da mayoritariamente en los municipios conurbados y en la AMCT. Con base en este hallazgo, se puede conjeturar que en el Estado de México la inmigración, como factor exógeno, viene a ser un elemento más que refuerza las persistentes diferencias en los perfiles educativos de las poblaciones urbano y rural; así como entre los

- La distribución de la población de $15-49$ según nivel de estudios para el total de la población (nativos y migrantes) del Estado de México es como sigue: sin estudios, 5.1; con primaria, 35.4; con secundaria, 35.2; con preparatoria y más, 24.3. Esta distribución se compara con los porcentajes correspondientes de la población nativa del Estado de México. Se debe advertir que el valor del índice establece cuán semejante o disímil resulta la distribución que se compara respecto a la que se toma como patrón de referencia. Para hacer algún comentario de corte valorativo se tiene que recurrir a la lectura de las distribuciones algún comentario de corte valorativo se

municipios conurbados y no metropolitanos. Dicho de otra manera, la selectividad de los migrantes en función de los niveles de estudio al favorecer más a las áreas más urbanizadas del Estado de México eleva los niveles promedios de escolaridad de la población total de dichas áreas, al tiempo que acentúa las disparidades cuando se les compara con la población de las localidades rurales.

Población femenina de 15-49 años segúnla condición de actividad y el nivel de estudios

Se debe mencionar que la separación de las mujeres de 15-49 años en dos grandes grupos de edad, 15-34 y 35-49, permite hacer algunas observaciones relativas a los niveles de participación de las mujeres y a las diferencias generacionales según la escolaridad.

Entre las integrantes de la población femenina del primer grupo, de edades 15-34, constituido por las distintas generaciones nacidas entre 1956 y 1975, se encuentran las beneficiarias de la expansión del sistema educativa que se caracterizó por una disminución importante del analfabetismo y por incrementos notorios en la educación postprimaria (Morelos et al., 1995).

En los municipios conurbados y localidades de corte rural la tasa de participación de la población femenina en edades 15-34 es de $20.6 \%$; en las de tipo urbano sube a 27.5 por ciento. Las tasas de desocupación ${ }^{10}$ son de 11.8 y 10.0 para las localidades de menos de 15 mil y con más de 15 mil habitantes respectivamente. Estos mismos indicadores para la población femenina de 35-49 años arrojan los siguientes valores: tasas de participación de 15.3 y $27.5 \%$, y de desocupación de 8.8 y 2.9 por ciento.

En las localidades rurales del área metropolitana de la ciudad de Toluca los porcentajes son inferiores a los de las urbanas. En las edades de 15-34 la tasa de actividad en las localidades rurales es de 17.4, y en las urbanas de 27.9. Las tasas de desocupación muestran un comportamiento inverso al observado en los conurbados, pues los porcentajes indican mayor desocupación en las localidades urbanas.

En el grupo de edades 35-49 el diferencial en los niveles de participación y de desocupación entre grupos de edades y localidades

10 Ia tasa de desocupación está dada por el cociente entre la población desocupada en un grupo de edad dado y la población activa de dicho grupo de edad. 
según tamaño, son similares a los observados en los municipios conurbados. Para ambos tipos de localidades las tasas de actividad son de 15.7 y $33.4 \%$ respectivamente, y las de desocupación de 7.7 y 4.0 por ciento.

En los municipios no metropolitanos se observa un patrón igual al recién descrito, la diferencia es que los niveles en las tasas de actividad son inferiores tanto por grupos de edad como por tipo de municipios. Para el primer grupo los valores de las tasas son de 14.8 y $29.1 \%$; las correspondientes al siguiente grupo fluctúan entre 10.7 y 21.3 por ciento. El desempleo registra tasas de $13.3,9.4$ y $3.6 \%$ respectivamente (véase cuadro 7 ).

Los datos del cuadro 7, referidos a los municipios conurbados, documentan los diferenciales generacionales. Las integrantes de las generaciones 1956-1975 presentan porcentajes de población sin estudios inferiores a los de las generaciones 1941-1955; 6.2 contra 16.7 y 3.8 frente a 13.8 (véase la de Total para los grupos de edades y tipos de municipios). El comportamiento inverso se observa al comparar los porcentajes de mujeres con secundaria y preparatoria y más (véase los valores de la misma). El mismo patrón se observa en los cuadros 7a y 7b. Además, los porcentajes dibujan la situación de desventaja en que se encuentran los municipios no metropolitanos, aspecto que ya había sido señalado en el apartado de migración (véase cuadros 7a y 7b). En los cuadros 7, 7a y 7b los datos para las mujeres en los dos grupos de edad considerados y en los diversos municipios apuntan en el mismo sentido.

La proporción de mujeres sin estudios dedicadas a las labores del hogar es sistemáticamente mayor que la correspondiente a la de las mujeres ocupadas y desocupadas. Comparando las proporciones para las mujeres con secundaria y con preparatoria y más, los datos muestran valores más bajos para las mujeres que se dedican a las labores del hogar.

El examen comparativo de los cuadros 7, 7a y $7 \mathrm{~b}$ sugiere que las mujeres activas sin estudios se concentran en los municipios no metropolitanos y en los conurbados; los valores de esta categoría en el AMCT son los més bajos. En dicha área las proporciones de mujeres ocupadas con secundaria y más en los dos grupos de edades considerados superan a las correspandientes a los municipios conurbados y no metropolitanos en el caso de las localidades urbanas.

Cuadro 7

Estado de México: Población de 15-49 años por condición de actividad, nivel de estudios, urbano-rural y tipo de

municipio, 1990

(cifras relativas)

\begin{tabular}{|c|c|c|c|c|c|}
\hline \multirow{3}{*}{ - de 15000} & \multirow{2}{*}{\multicolumn{5}{|c|}{ Municiplos conurbados }} \\
\hline & & & & & \\
\hline & $\begin{array}{r}\text { Sinest } \\
406\end{array}$ & Primaria & Secund. & Prepayt & Total \\
\hline Desocupados & 4.35 & 60.87 & $\begin{array}{l}48.22 \\
21.74\end{array}$ & $\begin{array}{l}20.81 \\
13.04\end{array}$ & 100.00 \\
\hline Estudiantes & & 5.97 & 57.46 & 36.57 & 100.00 \\
\hline Hogar & 8.13 & 54.56 & 31.18 & 6.13 & 100.00 \\
\hline \multirow[t]{2}{*}{ Total } & $\begin{array}{r}100.00 \\
6.16\end{array}$ & 42.17 & 38.10 & 13.57 & $\begin{array}{l}100,00 \\
100,00\end{array}$ \\
\hline & \multicolumn{5}{|c|}{$35 \times 49$} \\
\hline Ocupados & 12.28 & 59.65 & 19.30 & 8.77 & 100.00 \\
\hline Desocupados & 40.00 & 20.00 & 20.00 & 20.00 & 100.00 \\
\hline Estudiantes & 100.00 & & & & 100.00 \\
\hline Hogar & 16.83 & 76.05 & 5.50 & 1.62 & 100.00 \\
\hline \multicolumn{4}{|l|}{$\begin{array}{l}\text { Otros } \\
\text { Total }\end{array}$} & 2.96 & 100.00 \\
\hline + de 15000 & \multicolumn{5}{|c|}{5 a 34} \\
\hline Ocupados & 2.42 & 27.87 & 42.45 & 27.26 & 100.00 \\
\hline Desocupados & 7.01 & 26.52 & 44.82 & 21.65 & 100.00 \\
\hline Estudiantes & 0.41 & 4.02 & 49.57 & 46.00 & 100.00 \\
\hline Hogar & 5.58 & 47.86 & 36.61 & 9.95 & 100.00 \\
\hline Otros & 5.56 & 33.33 & 38.89 & 22.22 & 100.00 \\
\hline \multirow[t]{2}{*}{ Total } & 3.78 & 33.57 & 40.87 & 21.78 & 100.00 \\
\hline & \multicolumn{5}{|c|}{35 a 49} \\
\hline Ocupados & 10.62 & 45.77 & 23.96 & 19.65 & 100.00 \\
\hline Desocupados & 5.56 & 55.56 & 25.00 & 13.89 & 100.00 \\
\hline Estudiantes & 11.11 & 55.56 & 16.67 & 16.66 & 100.00 \\
\hline Hogar & 15.16 & 62.59 & 15.47 & 6.78 & 100.00 \\
\hline Otros & 9.52 & 52.38 & 28.57 & 9.53 & 100.00 \\
\hline Towal & 13.80 & 57.84 & 17.94 & 10.42 & 100.00 \\
\hline
\end{tabular}


Cuadro $7 \mathbf{a}$

Estado de México: Población de 15-49 años por condición de actividad, nivel de estudios, urbano-rural y tipo de

municipio, 1990

(cifras relativas)

\begin{tabular}{|c|c|c|c|c|c|}
\hline \multirow[b]{3}{*}{ de 15000} & \multirow{2}{*}{\multicolumn{5}{|c|}{ Área metropolitana de la ctudad de Toluca }} \\
\hline & & & & & \\
\hline & Sin est. & Primaria & Secund. & Prepay+ & Tolat \\
\hline Ocupados & 1.90 & 42.86 & 39.05 & 16.19 & 100.00 \\
\hline Desocupados & 11.11 & 44.44 & 33.33 & 11.12 & 100.00 \\
\hline Essudiantes & & 12.31 & 53.85 & 33.84 & 100.00 \\
\hline Hogar & 14.04 & 59.81 & 22.03 & 4.12 & 100.00 \\
\hline Orios & & 100.00 & & & 100.00 \\
\hline \multirow{2}{*}{ Tool } & 10.12 & 52.24 & 28.19 & 9.45 & 100.00 \\
\hline & \multicolumn{5}{|c|}{$35 \times 49$} \\
\hline \multicolumn{6}{|l|}{$\begin{array}{l}\text { OCupados } \\
\text { Desocupados }\end{array}$} \\
\hline \multicolumn{6}{|l|}{ Estudiantes } \\
\hline Hogar & 34.97 & 53.01 & 2.73 & 9.29 & 100.00 \\
\hline \multicolumn{6}{|c|}{$\begin{array}{r}100.00 \\
44.35\end{array}$} \\
\hline Tooul & 29.03 & 44.35 & 3.63 & 22.98 & 100.00 \\
\hline \multicolumn{6}{|l|}{+ de 15000} \\
\hline Ocupados & 1.85 & 19.93 & 42.07 & 36.15 & 100.00 \\
\hline Desocupados & 9.68 & 9.68 & 38.71 & 41.93 & 100.00 \\
\hline Estudiantes & 0.51 & 4.10 & 48.72 & 46.67 & 100.00 \\
\hline \multirow{2}{*}{\multicolumn{6}{|c|}{ Oros }} \\
\hline & & & & & \\
\hline Tomal & \multicolumn{5}{|c|}{35 a 49} \\
\hline Ocupados & 7.26 & 29.03 & 42.74 & 20.97 & 100.00 \\
\hline Desocupedos & 40.00 & 20.00 & 20.00 & 20.00 & 100.00 \\
\hline Estandiantes & & & 100.00 & & 100.00 \\
\hline Hogar & 14.52 & 53.53 & 23.24 & 8.71 & 100.00 \\
\hline Tomal & 12.40 & 44.74 & 29.92 & 12.94 & 100.00 \\
\hline
\end{tabular}

Fuente: Elbboractones del autor.
Cuadro $7 \mathbf{b}$

Estado de México: Población de 15-49 años por condición de actividad, nivel de estudios, urbano-rural y tipo de municipio, 1990

(cifras relativas)

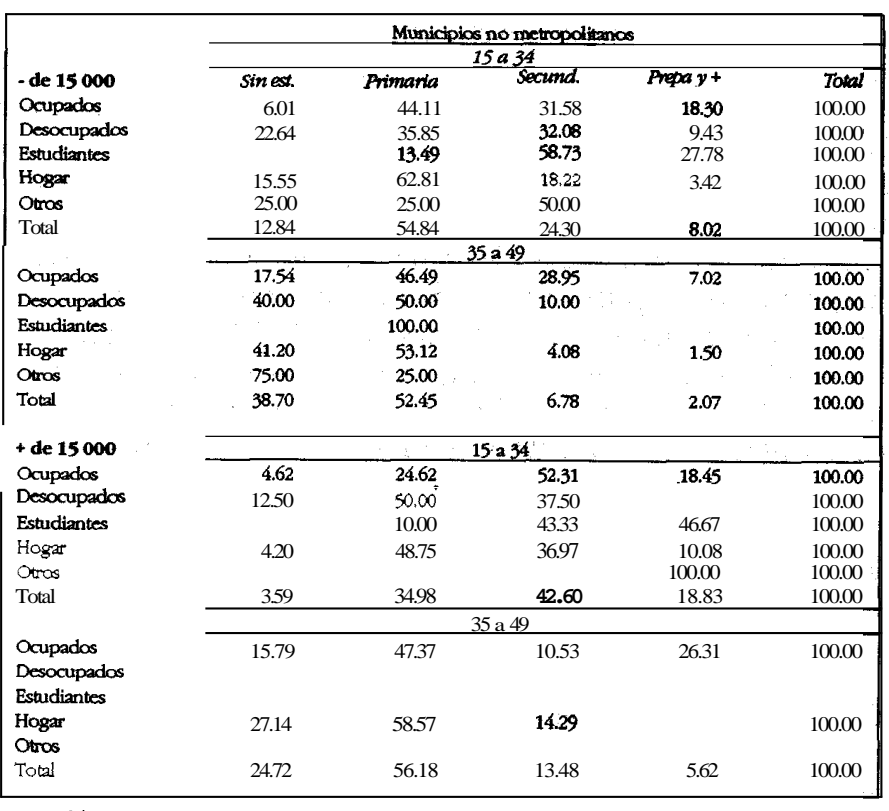


Con referencia al grupo de edad 15-34 en los municipios rurales, los valores más altos en las proporciones antes citadas corresponden a los municipios conurbados y los más bajos a los no metropolitanos. En el caso de la población entre 35 y 49 años, ya sea que se tomen como referencia los valores de las proporciones ya citadas de los municipios conurbados o los de los no metropolitanos, éstos se encuentran en un nivel inferior que los consignados para el AMCT.

En resumen, los datos indican que los perfiles educativos de la población con mayores niveles de escolaridad se encuentran entre la población residente en las localidades urbanas, ya sea que participe o no en la producción de bienes y servicios. Asimismo, muestran de forma clara la presencia de desigualdades educativas entre las integrantes de las generaciones nacidas entre 1941-1955 comparadas con las pertenecientes a las cohortes de 1956-1975 ${ }^{11}$. De igual modo los perfiles educativos de las mujeres activas y las dedicadas a las labores del hogar son consistentes con los encontrados en otros trabajos (Morelos et al., 1995; Jusidman y Eternod, 1994).

\section{TERCERAPARTE}

DIFERENCIALES DE LA MORTALIDAD EN LAS PRIMERAS EDADES

En razón del relativo desconocimiento que se tiene en el Estado de México sobre los niveles de la mortalidad infantil $(Q(1))$ y de la niñez $(\mathrm{Q}(5))$ según diversas características, se presentan en los cuadros 8 al 13 las estimaciones de estos indicadores, las cuales, como ya se mencionó, están referidas a las madres entre los 20 y 24 años de edad.

${ }^{11}$ Aunque las integrantes de estas generaciones están en términos educativos en desventaja al comparárseles con las nacicos después de 1955, la cohorte nacida entre 1941-1946es una de las etiquetadas como pioneras por haber sido de las primeras en la príctica de la regulación de la fecundidad (Juárez y Quilodrán, 1996). Es dable pensar que si las pioneras hubieran tenido perfiles educativos similares al de las generaciones nacidas después de 1955, el cambio demográfico se hubiera dado anticipadamente, $\mathbf{y}$ posiblemente las presiones poblacionales sobre la vivienda, la educación y el empleo hubiesen sido de menor cuantía.

Las categorías espaciales y el comportamiento de la mortalidad en las primeras edades

En el cuadro 8 se consignan los valores de la $\mathrm{Q}(1)$ y $\mathrm{Q}(5)$ para los diferentes arreglos espaciales y según el tamaño de población de las localidades. Para el total de la entidad los datos del citado cuadro sugieren que los niveles más bajos los registran los municipios conurbados, con 31 defunciones por cada mil nacidos vivos y los más elevados los no metropolitanos, con 47 por mil. En las localidades con menos de 15 mil habitantes el patrón se modifica, ya que el AMCT es la que registra los valores más bajos, 40 por mil; mientras que los más altos corresponden a los municipios conurbados. En cambio, las localidades urbanas pertenecientes a la categoría de conurbados registran los valores más bajos, 29 defunciones de menores de un año y 35 de menores de cinco, respectivamente (véase cuadro 8).

Las tasas de mortalidad infantil de las localidades rurales resultan superiores en $62 \%$ a las de las localidades con una población por arriba de los 15 mil habitantes. En los municipios conurbados el diferencial es ligeramente mayor que el estatal. En cambio, en el área metropolitana de Toluca la brecha entre ambos tipos de localidades se reduce.

Diferenciales en la mortalidad de la niñez según la disponibilidad de agua y drenaje dentro de la vivienda

Las estimaciones correspondientes a la mortalidad de menores de un año y a la de los menores de cinco años según dispongan o no de agua entubada dentro del terreno o de la vivienda, así como las respectivas para las viviendas con o sin drenaje, aparecen en el cuadro 9. Disponer de agua y contar con drenaje dentro de la vivienda reduce los riesgos de muerte de la población de menores de cinco años. Pero el riesgo es menor para aquellas poblaciones que residen en las localidades de más de 15 mil habitantes y mayor para los pequeños que habitan en los municipios no metropolitanos.

En el caso de la población que no cuenta con agua entubada dentro de la vivienda ni del terreno, el ordenamiento (de mayor a menor) de los valores del indicador citado es como sigue: municipios no metropolitanos, localidades rurales, AMCT, municipios conurbados y localidades con más de 15 mil habitantes (véase cuadro 9). 
Cuadro 8

Estado de México: Tasas de mortalidad infantil y de la niñez por tamaño y tipo de municipios hacia 1988

$$
\text { (por mil) }
$$

\begin{tabular}{|c|c|c|c|c|c|c|}
\hline \multirow[t]{2}{*}{ Thpostiam. } & \multicolumn{2}{|c|}{15000} & \multicolumn{2}{|c|}{$15000 y+$} & \multicolumn{2}{|c|}{ Total } \\
\hline & $Q(1)$ & $Q(S)$ & $Q(1)$ & $Q(5)$ & $Q(1)$ & $Q(5)$ \\
\hline Estado & 47 & 61 & 29 & 35 & 36 & 44 \\
\hline Conurbados & 49 & 63 & 29 & 35 . & 31 & 38 \\
\hline ZMCT & 40 & so & 33 & 26 & 37 & 45 \\
\hline No metrop. & 48 & 63 & & & 47 & 60 \\
\hline
\end{tabular}

Cuadro 9

Estado de México. Tasas de mortalidad infantil y de la niñez según servicios dentro de la vivienda y tipo de

municipios, 1988

(por mil)

\begin{tabular}{|c|c|c|c|c|}
\hline \multirow[b]{3}{*}{ Essodi } & \multicolumn{2}{|c|}{ Con agua } & \multicolumn{2}{|c|}{ Sin agua } \\
\hline & $Q(1)$ & $Q(5)$ & $Q(1)$ & $2(5)$ \\
\hline & 31 & 38 & 50 & 65 \\
\hline-15000 & 42 & 53 & 57 & 76 \\
\hline $15000 y+$ & 27 & 33 & 40 & 50 \\
\hline Conurbados & 29 & 35 & 44 & 56 \\
\hline & 39 & 49 & 56 & 75 \\
\hline \multirow{2}{*}{ No metrop. } & & 47 & \multirow{2}{*}{\multicolumn{2}{|c|}{$\begin{array}{l}\text { so } \\
\text { Sin drenaje }\end{array}$}} \\
\hline & \multicolumn{2}{|c|}{ Con drenaic } & & \\
\hline Estado & 26 & 31 & 51 & 67 \\
\hline-15000 & 31 & 38 & 54 & 72 \\
\hline $15000 y_{+}$ & 25 & 29 & 45 & 58 \\
\hline Comurbedos & 26 & 31 & 48 & 62 \\
\hline & 23 & 27 & 53 & 70 \\
\hline No metrop. & 27 & 32 & 54 & 71 \\
\hline
\end{tabular}

Fuente: Eleboraciones del autor.
Respecto al diferencial de la mortalidad infantil según tengan las viviendas drenaje o carezcan del mismo, una vez más las localidades con menos de 15 mil habitantes y los municipios no metropolitanos registran las tasas más altas de mortalidad en la infancia y la niñez. Se observa una situación similar en el caso de las viviendas sin drenaje, con la salvedad de que las diferencias se reducen al compararse las estimaciones de la mortalidad infantily de la niñez correspondientes a las localidades según tamaño y categorías (véase cuadros 9 y 10).

Mortalidad de los menores de cinco años según el estado civil de sus madres

En la primera parte del cuadro 10 se consignan los valores de las tasas de la mortalidad infantil y de la niñez según el estado conyugal (solteras y unidas) de las mujeres. En el caso de las mujeres "unidas" se repiten los principales rasgos del patrón ya observado en el caso de las viviendas que disponen de agua dentro de la misma. Esto es, los valores más altos los registran las poblaciones de las localidades de menos de 15 mil habitantes y las de los municipios no metropolitanos. Los hijos menores de cinco años de madres solteras de las localidades rurales enfrentan un riesgo doblemente mayor que el que tienen los hijos de estas madres pero que viven en localidades urbanas. Según las estimaciones, en las localidades urbanas el diferencial entre solteras y casadas es inexistente, y de poca importancia entre las localidades rurales.

La mortalidad de la niñez entre nativas y migrantes

En la parte inferior del cuadro $\mathbf{1 0}$ se presentan las valores de estos indicadores para las mujeres según sean nativas o migrantes. A diferencia de las estimaciones previas, las tasas de la mortalidad infantil y de la niñez según el lugar de nacimiento de las mujeres muestran comportamientos distintos. La lectura horizontal del citado cuadro indica que las mujeres migrantes presentan valores más bajos que los de las nativas, en los siguientes casos: entidad, AMCT y municipios no metropolitanos; en los otros casos el patrón se invierte.

El examen vertical (columnas) de los valores sugiere que las mujeres nativas de la entidad residentes en las localidades urbanas 
Cuadro 10

Estado de México. Te mortalidad infartil y de la niñez según estado conyugal de la mujer, lugar de nacimiento de la madre y tipo de municipios, hacia 1988

\section{(por $\mathbf{m i l}$ )}

\begin{tabular}{|c|c|c|c|c|}
\hline & \multicolumn{4}{|c|}{ Estado comprigal } \\
\hline & \multicolumn{2}{|c|}{ Unidas } & \multirow{2}{*}{\multicolumn{2}{|c|}{ Solteras }} \\
\hline & $Q(1)$ & $Q(5)$ & $Q(1)$ & \\
\hline Estado & 28 & 34 & 27 & 32 \\
\hline-15000 & 39 & 48 & 43 & 55 \\
\hline $15000 y^{+}$ & 22 & 26 & 21 & 24 \\
\hline Conurbados & 24 & 29 & 21 & 24 \\
\hline $\mathrm{ZMCT}$ & 31 & 38 & & \\
\hline \multirow[t]{3}{*}{ No metrop. } & 38 & & & \\
\hline & \multicolumn{4}{|c|}{ Lugar de nadimiento } \\
\hline & & & & \\
\hline Estado & 38 & 47 & 32 & 39 \\
\hline-15000 & 47 & 60 & 54 & 72 \\
\hline $15000 y+$ & 29 & 35 & 30 & 36 \\
\hline Conurbados & 31 & 37 & 32 & 39 \\
\hline ZMCT & 37 & 46 & 35 & 43 \\
\hline No metrop. & 48 & 62 & 34 & $\$ 2$ \\
\hline
\end{tabular}

Cuadro 11

Estado de México. Tasas de mortalidad infantil y de la niñez segun condición de actividad de la madre, hacia 1988 (por $\mathbf{m i l}$ )

\begin{tabular}{|lllll|}
\hline & \multicolumn{4}{c|}{ Condición de actioidad } \\
\cline { 2 - 5 } & \multicolumn{3}{c|}{ Activa } & mactiva \\
\cline { 2 - 5 } & $Q(5)$ & $Q(5)$ & $Q(1)$ & $Q(5)$ \\
Estado & 30 & 36 & 37 & 46 \\
-15000 & 40 & 50 & 41 & 52 \\
$15000 \mathrm{y}+$ & 26 & 31 & 30 & 36 \\
Conurbados & 27 & 33 & 40 & 50 \\
ZMCT & 31 & 38 & 48 & 62 \\
No metrop. & & & & \\
\hline
\end{tabular}

Puente: Elaboraciones del autoc. registran las menores tasas del mortalidad infantil y de la niñez. Los valores más altos corresponden una vez más a los municipios no metropolitanos, seguidos, en orden decreciente, por las tasas correspondientes a las localidades con menos de 15 mil habitantes, al AMCT y a los municipiosconurbados. Para las mujeres migrantes el ordenamiento de los valores de las tasas es casi el mismo. Como se puede apreciar, haciendo la lectura por filas, las diferencias en los distintos valores son de poca monta, resultado similar al que sugieren los datos de uno de los estudios sobre el tema ya mencionado (Bronfman y Tuirán, 1984).

\{Influye el trabajo de la madre en los niveles de mortalidad de sus hijos?

En forma sistemática, las mujeres que participan en la actividad económica en las localidades urbanas o rurales, en los conurbados y no metropolitanos, presentan tasas de mortalidad en las primeras edades inferiores a las de las mujeres que no trabajan (veáse cuadro 11). Las diferencias relativas a la condición de actividad son casi del mismo orden que las obtenidas con el criterio de lugar de nacimiento, y menores a las que arrojan las estimaciones basadas en el tamaño de la población de los municipios y servicios dentro de la vivienda.

Patrones de la mortalidad infantil y de la niñez según la escolaridad de la madre

En el Estado de México las tasas de mortalidad infantil y de la niñez entre las madres con secundaria y más son de 23 y 27 defunciones por mil respectivamente. Estos valores son tres veces més bajos que los correspondientes a las madres sin estudios, 70 y 96 por mil (veáse el cuadro 12). Si se comparan los datos para los distintos niveles de estudios se ve que las diferencias mayores se dan entre las mujeres con 1 a 3 años de primaria y aquellas con 4 a 6 años.

Los valores de las tasas de mortalidad en las primeras edades para las madres sin estudios y tamaño poblacional de las localidades sugieren que los riesgos de muerte para los hijos de estas madres son casi los mismos. En cambio, las mujeres con 1 a 3 años de primaria que viven en localidades de más de $\mathbf{1 5}$ mil habitantes tienen un riesgo de muerte inferior en $\mathbf{2 8 \%}$ al de las mujeres con similar nivel 
de escolaridad pero que viven en los ámbitos rurales. En la misma situación de desventaja se encuentran las mujeres con secundaria y més que residen en localidades cuya población es menor a los 15 mil habitantes. En cambio, los niveles de mortalidad infantil y de la niñez de madres con secundaria y más que viven en los municipios conurbados, AMCT y no metropolitanos se caracterizan por la semejanzas en sus valores (véase cuadro 12).

De lo anterior se infiere que las diferencias en los indicadores de la mortalidad en los primeros años y en los espacios metropolitanos tienden a ser menores al aumentar la escolaridad de la madre.

Mortalidad de los menores según niveles de estudio de la madre, disponibilidad de agua dentro de la vivienda y tamaño de localidad

Comparando las dos primeras columnas del cuadro 13 con las columnas 1 y 3 del cuadro 9, se observa que las mujeres con 1 a 3 años de educación primaria residentes en localidades rurales tenían un tasa de mortalidad-infantil $37 \%$ superior a la de las mujeres con igual escolaridad pero viviendo en áreas urbanas. Cuando se combinan la educación y la disponibilidad de agua dentro de la vivienda, se observa que la diferencia para las mujeres con el mismo nivel de escolaridad y que son residentes del medio rural aumenta a 58\%; o sea 11 puntos porcentuales por arriba del porcentaje que resulta cuando sólo se toman la escolaridad y el volumen de población de la localidad. Para las mujeres con 4 a 6 años de escolaridad se observa el mismo comportamiento, aunque el diferencial se reduce.

Para la población sin estudio que no dispone de agua, sus niveles indican una cierta independencia del tamaño de las localidades; no así en el caso de las mujeres con 4 a 6 años de primaria que no disponen de agua y viven en ámbitos rurales. Dichas mujeres enfrentan situaciones más adversas respecto a la salud de sus hijos que las que viven en las localidades urbanas, aunque carezcan del servicio de agua entubada dentro del terreno o de la vivienda.
Cuadro 12

Estado de México: Tasas de mortalidad infantil y de la niñez según escolaridad de la madre y tipo de municipio, hacia 1988 (por mil)

\begin{tabular}{|c|c|c|c|c|c|c|}
\hline & \multicolumn{6}{|c|}{ Tipo de muencicipio } \\
\hline & -15000 & $15000 y+$ & Comuert & ZNCT & Nomob. & Bstado \\
\hline \multicolumn{7}{|l|}{ Stin estudibos } \\
\hline$Q(1)$ & 69 & 68 & & & 62 & $w$ \\
\hline$Q(5)$ & 96 & 93 & & & 85 & 96 \\
\hline \multirow{2}{*}{\multicolumn{7}{|c|}{$\begin{array}{l}\text { Primarta } \\
\begin{array}{lll}1 & 3 & \text { años }\end{array}\end{array}$}} \\
\hline & & & & & & \\
\hline$Q(1)$ & 59 & 43 & 46 & & 66 & 52 \\
\hline Q(5) & 79 & 55 & 59 & & 91 & 69 \\
\hline \multicolumn{7}{|l|}{4 a 6 años } \\
\hline$Q(1)$ & 38 & 33 & 30 & 23 & 37 & 31 \\
\hline & 47 & 21 & 36 & 27 & 46 & 38 \\
\hline \multicolumn{7}{|l|}{ Secundarta + } \\
\hline Q(1) & 31 & 21 & 23 & 23 & 24 & 23 \\
\hline (5) & 38 & 25 & 27 & 27 & 28 & 27 \\
\hline
\end{tabular}

Cuadro 13

Estado de México: Tasas de mortalidad infantily de la niñez según escolaridad de la madre y tipo de municipio y disponibilidad de agua dentro de la vivienda, hacia 1988 (por mil)

\begin{tabular}{|c|c|c|c|c|}
\hline \multirow{3}{*}{$\begin{array}{l}\text { Con agua } \\
\text { Analfabetis }\end{array}$} & \multicolumn{2}{|c|}{ Menos de 15050} & \multirow{2}{*}{\multicolumn{2}{|c|}{ Masde 15000}} \\
\hline & $Q(1)$ & $\Omega(5)$ & & \\
\hline & & & & \\
\hline 1 a 3 años & 49 & 63 & 31 & 37 \\
\hline 426 años & 31 & 38 & 25 & 30 \\
\hline Secund. $y+$ & 26 & 31 & 22 & 25 \\
\hline Shagara & & & & \\
\hline Analfabetas & 57 & 75 & 55 & 73 \\
\hline 1 a 3 años & 67 & 92 & & \\
\hline $\begin{array}{l}4 \text { a } 6 \text { años } \\
\text { Secund. } x+4\end{array}$ & 48 & 62 & 38 & 48 \\
\hline
\end{tabular}


Discusión

Las estimaciones de la mortalidad infantil y de la niñez reproducen el mismo patrón que el documentado a nivel nacional y regional en los diversos estudios consultados. Las variables que mayormente discriminan los riesgos de muerte de los niños en las primeras edades son la educación de la madre, los servicios dentro de la vivienda y el lugar de residencia. Para apoyar esta observación se calculó un índice relativo tomando como patrón de referencia el nivel de la mortalidad infantil de las madres con secundaria y más correspondiente a las localidades que cuentan con una población superior a los 15 mil habitantes. Los resultados, que nos dan una idea del ordenamiento de mayor a menor, aparecen en el cuadro 14.

La lectura por columnas muestra que de los cinco valores más altos los primeros dos corresponden a las madres sin estudios y a aquellas con 1 a 3 años de primaria, sea que se elija el estado o cualquier tipo de municipio y tamaño de localidad; después aparecen los índices para los servicios dentro de la vivienda. Los valores más bajos corresponden a la variable estado conyugal (unidas y solteras).

El examen por fila del cuadro 14 muestra, en forma clara, la situación de desventaja en que se encuentran los hijos de madres analfabetas que son migrantes, trabajan, son madres solteras, viven en viviendas sin agua y sin drenaje, y que residen en los municipios no metropolitanos y en las áreas rurales. En situación más ventajosa se encuentran los hijos pequeños de las madres más escolarizadas que viven en las localidades de más de 15 mil habitantes. Entre ambos extremos se localizan los habitantes de los municipios conurbados y del AMCT. En estos dos últimos destacan los valores altos del índice atendiendo a la falta de agua dentro de la vivienda y a las viviendas sin escusado (véase cuadro 14).

Según el informe de la Encuesta Nacional de Fecundidad y Salud de 1987 (DGPF, 1988), los niveles de mortalidad infantil entre los hijos de las mujeres sin estudios son tres veces más altos que las defunciones de menores de un año de las mujeres con secundaria y más. Para los niños menores de cinco años la relación resulta ser algo mayor que la anterior ${ }^{1 *}$. En los estados fronterizos dicha relación es ligeramente más alta, 3.3 a 1 (véase Núñez, 1992, cuadro 8.2).

12 Ambos indicadores están referidos al periodo 1977-1987. Las tasas de mortalidad infantil pan las mujeres sin educación y con secundaria y más san: 82.7 y 27.4 por mil. Las de la niñez de 113.7 y 28.6 por mil (DGPF, 1988, cuadro 9.3). 
Con relación al supuesto de que el cambio más brusco se daba entre los categorías de madres sin estudios y madres con primaria incompleta hay que mencionar algunos hallazgos. Para el periodo 1977-1987 la diferencia asciende a 19 puntos por mil, que es la mayor discrepancia que se presenta entre los cuatro niveles de estudio considerados (veáse DGPF, 1988, cuadro 9.3). En la región fronteriza la brecha es mayor, 40 puntos por mil (veáse Núñez, 1992, cuadro 8.2). Hacia 1990 la mayor diferencia, 22 puntos por mil, era la que resultaba al comparar las tasas de la mortalidad infantil de madres con primaria y la de las madres con secundaria y más (Aguirre et al., 1995, cuadro 1).

En el Estado de México los valores estimados indican que el cambio más pronunciado se da entre las madres con $\mathbf{1}$ a $\mathbf{3}$ años de educación primaria y aquellas con 4 a 6 años. Tal resultado sitúa al Estado de México en una situación peculiar. La mayor diferencia se presenta entre las dos categorías intermedias, entre las madres con 1 a 3 años de primaria y las que tienen de 4 a 6 años; situación distinta a la que sugieren los dos primeros estudios (veáse DGPF, 1988, cuadro 9.3; Núñez, 1992, cuadro 8.2) y diferente a la existente en el país en 1990 (Aguirre et al., 1995, cuadro 1). Se puede aducir que en los estudios citados, la categoría primaria incompleta o alfabeta no corresponde en estricto sentido con el grupo de madres con 1 a 3 años de educación primaria". La falta de criterios uniformes sobre las categorías educativas utilizadas en los distintos estudios imposibilita que se acepte o rechace la validez del supuesto que se formuló al respecto.

En relación con la hipótesis relativa al menor influjo de los factores espaciales de las tasas de mortalidad infantil para las madres más escolarizadas, cuando menos en dos estudios (García España y Mojarro, 1982; Aguirre et al.,1995) en los que se presentan las tasas de mortalidad infantil clasificadas por lugar de residencia y escolaridad de la madre, los resultados sirven de apoyo a tal suposición. En el primer trabajo las diferencias en las tasas de mortalidad para los menores de tres años en los ámbitos urbano y metropolitano reflejan una diferencia de 2 puntos por mil. En el

13 En ambos estudios no se explica a cuántos años corresponde la categoría de primaria incompleta. En el tercer trabajo las alfabetizadas son las madres que declararon saber leer y escribir, $\mathbf{y}$ la categoría de primaria incluye a las madres con primaria incompleta y completa. En caso de que no exista correspondencia en los años de estudio, la diferencia podría atribuirse a la falta de criterios similares. Tal ausencia explica la presencia de la mayor discrepancia, en 1990, entre las madres con primaria y secundaria y más. segundo la diferencia sube a 4.4 puntos por mil entre las localidades de menos de 2,500 y las de 100,000 y más.

En el Estado de México las diferencias entre las localidades rurales y urbanas y tipos de municipios fluctúan entre 7 y 10 puntos por mil. Si se excluyen de la comparación las localidades rurales la diferencia máxima es de 3 puntos por mil (véase cuadro 12). El comportamiento descrito permite afirmar que la variabilidad de las tasas de mortalidad infantil y de la niñez entre las madres con secundaria y más se reduce notoriamente en las localidades urbanas, ya sea que se ubiquen en los municipios conurbados, en el AMCT o en los no metropolitanos. En estos contextos el desarrollo y alcances de la infraestructura de salud, la capacidad económica de la familia para acceder a la medicina privada, la aplicación oportuna de medidas preventivas y curativas, la asociación entre nivel de escolaridad y oportunidades ocupacionales y posibilidadesdeobtener mayores ingresos pueden contribuir al abatimiento de los diferenciales en los niveles de la mortalidad entre las madres más escolarizadas. Por el contrario, en las poblaciones rurales la educación de las madres suple las desigualdades en la dotación de servicios médicos y de servicios dentro de la vivienda. Pero en el caso de las madres analfabetas, la carencia de estudios puede convertirse en un factor que gravite negativamente en las condiciones de salud de sus hijos.

Respecto a los diferenciales según lugar de residencia, para facilitar la comparación con los resultadosconsignados en el informe de la Encuesta de Fecundidad y Salud de 1987, se calculó el promedio de los valores de las localidades de menos de 2,500 y de 2,500-19,999 habitantes. Las tasas de mortalidad así estimadas son 70.1 y 90.6 por mil para los niños menores de $\mathbf{1}$ y $\mathbf{5}$ años respectivamente". Comparando dichos valores con los respectivos de las localidades urbanas, las diferencias son de 30 puntos por mil en el caso de la $\mathrm{Q}(1) \mathrm{y}$, de 43 puntos por mil en la $\mathrm{Q}(5)$.

Usando el mismo procedimiento para obtener la media simple de las tasas de mortalidad infantil, en 1992 la diferencia entre

${ }^{14}$ El informe de la Encuesta de Fecundidad y Salud de 1987 presenta los datos sobre mortalidad infantil y de la niñez según el lugar de residencia como sigue: Lugarde Residencia $-2,500$ $2,500-19,999$

20,000 y más Áreas metropolitanas

$\begin{array}{ll}\mathrm{Q}(1) & \mathrm{Q}(5) \\ 78.8 & 103.5 \\ 61.6 & 77.7 \\ 40.2 & 47.7 \\ 28.6 & 31.5\end{array}$


las localidades urbanas y rurales era de 13.6 puntos por mil (véase Aguirre et al., 1995, cuadro 1).

En el Estado de México las diferencias en las localidades urbanas y rurales es de 18 y 26 puntos por mil, según se comparen las tasas de mortalidad infantil o las de la niñez. El valor correspondiente a la tasa de mortalidad de los menores de 1 año se sitúa entre los valores estimados con los datos de Aguirre et al. y los del Informe de la Encuesta de Fecundidad y Salud de 1987. Diferencias del mismo orden de magnitud se obtienen cuando se utilizan las probabilidades de muerte entre el nacimiento y el segundo año de edad ${ }^{15}$.

Pese al empleo de criterios disímiles para hacer los cortes de lo urbano y lo rural, las diferencias parecen consistentes con el patrón reportado en otros estudios. Sin embargo, su magnitud puede verse afectada por el empleo de criterios distintos.

Un problema similar emerge cuando se comparan los diferencias numéricas entre las tasas de mortalidad de los menores según los servicios en la vivienda ${ }^{16}$. En el multicitado estudio de Bronfman y Tuirán los valores de la probabilidad de muerte para las viviendas con calidad deficiente y satisfactoria fluctúan entre 92.5 y 53.6; la diferencia es de 29 puntos. En nuestro caso, la mayor diferencia entre las viviendas que disponen de aguan dentro de las mismas y las que no cuentan con este servicio corresponde a los municipios no metropolitanos, siendo de 22 puntos por mil. Las relativas al drenaje (viviendas con drenaje versus viviendas sin drenaje) son en el AMCT y en los no metropolitanos de 30 y 27 puntos por mil respectivamente.

Con referencia a la condición de actividad combinada con el lugar de residencia, se encontró que las mujeres que trabajaban y que vivían en las áreas urbanas y/o metropolitanas registraron tasas de mortalidad más bajas para los menores de tres años que las de las madres dedicadas a las labores del hogar. Un resultado consistente con lo recién expresado se obtiene cuando, en lugar de la tasa de

is Las estimacionespan el periodo 1965-1979 de la tasa de mortalidad de menores de dos años, Q(2) (veáse Bronfman y Tuirán, 1984), los valores para las localidades rurales (menos de 20 mil habitantes), superan en 25 puntos por mil a los de las localidades urbanas (más de 20 mil habitantes). Los mismos indicadores de ambas tipos de localidades pero para el periodo 1976-1985 (Bronfman, 1990) arrojan una diferencia de 30 puntos.

${ }^{16}$ Los autores de algunos de los trabajos consultados construyen índices de servicios de la vivienda e índices sanitarios de la misma. Éstos serian los mas compambles, ya que en su construcciónse combinan la disponibilidad de agua y de drenaje dentro o fuera de la vivienda. mortalidad infantil, se emplea el tipo de riesgo. La mayor proporción de mujeres con riesgo bajo corresponde a aquellas que siempre han trabajo. La diferencia es casi $15 \%$ superior al de las que nunca trabajaron.

En el Estado de México la mortalidad diferencial de los menores de cinco años según la condición de actividad de la madre es consistente con los hallazgos basados en tipo de riesgo y en los referidos a los ámbitos urbanos, pero con la característica que dicho diferencial se observa también en las localidades rurales.

La participación de la mujer en las actividades económicas influye de manera directa e indirecta sobre la salud de los hijos. En el primer caso afecta la duración o el tiempo dedicado al cuidado de éstos. El tiempo que le dedican las madres al trabajo compite con el tiempo que le dedican a la atención de los hijos pequeños. Este efecto puede influir negativamente en la salud de los hijos, en especial cuando la madre trabajadora no cuenta con redes familiares y sociales mediante las cuales se supla su presencia. El segundo, opera vía los mecanismos educación-ocupación-ingreso; educaciónacceso y uso de los servicios de salud. Provisionalmente, y de acuerdo con los resultados, se puede adelantar que el efectó directo se ve contrarrestado por el indirecto.

Por otra parte, la mayor escolaridad de las migrantes respecto a las nativas puede estar influyendo en la existencia de diferenciales en los indicadores utilizados en el estudio. Tal como se planteaba en el caso de la migración internacional, la influencia indirecta de la migración vía la educación, la participación en las actividades productivas y la obtención de mayores ingresos pueden estar explicando la presencia de las diferencias ya aludidas.

De acuerdo con el análisis de los niveles y de los diferenciales de la mortalidad en las primeras'edades, se puede afirmar que para influir en los niveles de la mortalidad de los menores de cinco años, además de las acciones de corte vertical que periódicamente se llevan a cabo en la entidad, se tienen que realizar las de corte horizontal. El conjunto de acciones debe de estar dirigido en forma prioritaria a dotar de los servicios de agua y drenaje a las viviendas de las localidades rurales; y en forma simultánea atender las carencias de estos servicios que se presentan en el AMCT y en los municipios conurbados. Este último tipo de medidas tiene una relación estrecha con el progreso social. El avance social impone como condición la satisfacción de las necesidades básicas de la población. 
Desde la perspectiva social, la recomendación obvia es elevar los niveles de escolaridad de la población femenina de 15 y más años. Estos esfuerzas deben focalizarse preferentemente en las localidades con menos de 15 mil habitantes y en aquellos espacios metropolitanos en donde la concentración de población analfabeta sea importante, como podría ser el caso de los conurbados en donde se concentra la población migrante analfabeta.

Una segunda medida consistiría en diseñar paquetes de educación en salud de los menores para ser aplicados mediante los sistemas de educación informal en los ámbitos urbanos y rurales de la entidad mexiquense. Para poner en práctica esta medida es indispensable que exista la coordinación entre las distintas instancias estatales de los sectores educativos y de salud, y de éstas con las dependencias respectivas del gobierno federal, para discutir y elaborar los contenidos de los paquetes educativos, capacitar a las instructoras y llevar a cabo en forma permanente y sistemática el conjunto de actividades requeridas según la filosofía de los sistemas de educación informal.

Una tercera recomendación tiene que ver con la necesaria coordinación entre el Consejo Estatal de Población y el Consejo Nacional de Población para diseñar o rediseñar los contenidos ad hoc de las campañas publicitarias relativas a la salud reproductiva, con énfasis en la salud de los menores de edad. Dichos contenidos deben atender primordialmente las características y rasgos culturales de la población mexiquense: analfabeta, con primaria incompleta y que viven en las localidades rurales y municipios no metropolitanos; y en forma simultánea evaluar y decidir acerca de cuál o cuáles medios utilizar para llegar a la población objetivo.

Bibliografía

Aguado López, Eduardo (1994), "La educación básica en el Estado de México, 1970-1990: la desigualdad regional", en Roberto Blancarte (coord.), Estado de México: perspectivas para la década de los 90, Zinacantepec, El Colegio Mexiquense/Instituto Mexiquense de Cultura, pp. 553-598.

(1995), "La equidad, una asignatura pendiente: acceso y resultados educativos en cuatro zonas del Estado de México", en Enrique Pieck Gochicoa y Eduardo Aguado López, Educación y pobreza: de la desigualdad social a la

\section{3-235.}

Aguirre, Alejandro, José B. Morelos y Rodrigo Pimienta (1995), "Diferenciales socioeconómicos de la mortalidad infantil en México, 1992”, ponencia presentada en la V Reunión Nacional sobre Investigación Demográfica en México de la SOMEDE, México.

Brass, W. (1968), The Demograpby of Tropical Africa, Princeton, Princeton University Press.

Bronfman, Mario (1990), "Mortality and social sectors: Recent trends", en Mario Bronfman, Brígida García, Fátima Juárez, Orlandina de Oliveira y Julieta Quilodrán, Social Sectors and Reproduction in Mexico, Demographic and Health Survey Analysis, núm. 7, El Colegio de México/The Population Council/DHS, pp. 15-21.

(1994), "Familia y mortalidad infantil: la tendencia a repetir muertes infantiles", en Memorias de la N Reunion Nacional de Investigación Demográfica en México, tomo 1, México, INEGI/SOMEDE, pp. 205-211.

y Rodolfo Tuirán (1984), "La desigualdad social ante la muerte: clases sociales y mortalidad en la niñez", en Memorias del Congreso Latinoamericano de Población y Desarrollo,México, El Colegio de México-UNAM-PISPAL, vol. 1, pp. 187-219.

Camposortega, Sergio (1992), Análisis Demográfico de la Mortalidad en México 1940-1980, México, El Colegio de México.

Dirección General dePlanificación Familiar/Secretaría deSalud/DHS (1988), Encuesta Nacional sobre Fecundidad y Salud, 1987, México, Dirección General de Planificación Familiar.

Echarri, Carlos Javier (1995), "Estructura familiar y salud materno infantil", trabajo presentado en el Seminario Internaciona sobre las Consecuencias de las Transiciones Demográfica y Epidemiológica en América Latina, México, octubre 23-24. 
García España, Felipe y Octavio Mojarro (1982), "Algunos efectos del desarrollo en la mortalidad de la niñez en Méxicon, en Programa Nacional Indicativo, Memoria sobre la Segunda Reunión Nacional sobre la Investigación Demográfica en México, México, CONACYT, pp. 151-160.

García y Garma, Irma O. (1983), "Algunos factores asociados con la mortalidad infantil en Méxicon, Demografía y Economía, vol. XVII, núm. 3(55), pp. 289-320.

Gómez de León, José (1988), "Análisis multivarlado de la mortalidad infantil en México: un ejemplo del uso de modelos loglineales para estimar modelos de riesgos proporcionales", en Mario Bronfman y José Gómez de León, La mortalidad en México: niveles, tendencias y determinantes, México, El Colegio de México, pp. 333-367.

Graizbord, Boris y Alejandro Mina (1994), "Los ámbitos geográficos del componente migratorio de la ciudad de México", Estudios Demográficos y Urbanos, El Colegio de México, vol.9, núm.3, pp. 609-628.

Hernández M. Abelardo (1994/1995), "Comentarios a las cifras sobre magnitud de la población en el Estado de México ${ }^{\mathrm{n}}$, Roles de Población, Centro de Investigación y Estudios Avanzados en Población, UAEM, núms. 5-6, pp. 36-45.

Hobcraft J., J.W. McDonald y S. Rustein (1984), Socioeconomic factors in infant and child mortality: A crossnational comparison, Popukation Studies, vol. 38, pp. 193-233.

Holian, John (1989), Infant mortality and health care in mexican communities, Sol. Sci. Med., vol. 29, núm. 5, pp. 677-679.

Jiménez Ornelas, René (1988), Diferenciación social y mortalidad en menores de cinco años (estudio de tres grupos sociales), México, UNAM/CRIM.

(1993), “La mortalidad producto de la desigualdad social*, en Raúl Bejar Navarro y Héctor Hernández Bringas (coords.), Población y desigualdad social en México, México, UNAM/CRIM, pp. 203-228. y Alberto Menujin Zimud (1982), "Mortalidad infantil y clases sociales", en Memoria sobre la Segunda Reunión Nacional sobre Investigación Demográfica en México, México, CONACYT, pp. 33-41.

Juárez, Fátima (1996), "La formación de la familia y la movilidad a las áreas metropolitanas en México: un nuevo enfoque de la interacción entre los eventos demográficos", en Fátima Juárez, Julieta Quilodrán y Ma. Eugenia Zavala, Nuevas pautas reproductivas en México, México, El Colegio de México, pp. 147-198

y Julieta Quilodrán (1996), "Mujeres pioneras del cambio reproductivo en México", en Fátima Juárez, Julieta Quilodrán y Ma. Eugenia Zavala, Nuevas pautas reproductivas en México, México, El Colegio de México, pp. 97-118.

Jusidman, Clara y Marcela Eternod (1994), La participación de la población en la actividad económica en México, México, INEGI

Kanaiaupuni, Shawn Malia y Katherine Donato (1995), "Linking migration and health: Community and household effects of male migration on mothers and children in mexican origin cornrnunities", trabajo presentado en el Seminario Internacional sobre las Consecuencias de las Transiciones Demográfica y Epidemiológica en América Latina, México, octubre 23-24.

Martínez, Carolina (1992), "Recursos sociodemográficos y daños a la salud en unidades domésticas campesinas del Estado de México", Estudios Demográficos y Urbanos, vol. 7, núms. 2 y 3 , pp. 451-463.

(1994), "Algunas consideraciones en torno a los riesgos para la salud infantil y preescolar a partir de un estudio de cason, en Memorias de la $I V$ Reunión Nacional de Investigación Demográfica en México, tomo I, México, INEGI/SOMEDE, pp. 212-218. 
Medina López, Vicente (1994), "Análisis de la mortalidad infantilen México", en Memorias de la IV Reunión Nacional de Investigación Demográfica en México, tomo 1, México, INEGI/SOMEDE, pp. 180-191.

Menujin, Alberto, Gabriel Vera, Graciela Ruiz y René Jimenez (1984), "Factores sociodemográficos asociados a la mortalidad infantil ${ }^{\mathrm{n}}$, en Memorias del Congreso Latinoamericano de Población y Desarrollo, México, El Colegio de México-UNAM-PISPAL, vol. 1, pp. 221-250.

Mina, Alejandro (1981), "Estimaciones de los niveles, tendencias y diferenciales de la mortalidad infantily en los primeros años de vida en México, 1940-1977”, Demografía y Economía, vol. 15, núm.1, pp. 85-142.

Mojarro, Octavio y Ramón Aznar (1986), "Influencia de los factores biológicos y de la estructura social en la mortalidad infantil, 1965-1974”, en Jorge Martínez Manautou, Planificación familiar, población y salud en el México rural, México, IMSS, pp. 347-382.

y Leopoldo Núñez (1988), "Mortalidad infantil en México: tendencias y factores determinantes ${ }^{\mathrm{n}}$, Salud Pública Mex. vol. 30, núm. 3, pp. 329-345.

Morelos, José B.; Alejandro Aguirre y Rodrigo Pimienta (1995) - "Algunas observaciones sobre los niveles de escolaridad de la población activa mexicana, 1992", ponencia presentada en la V Reunión Nacional sobre Investigación Demográfica en México de la SOMEDE, México.

(1996), "Estado de México: análisis de algunos determinantes de la mortalidad infantil a nivel municipal ${ }^{\mathrm{n}}$ (en prensa en Estudios Sociológicos, núm. 41)

Negrete, María Eugenia (1995), "Evolución de las zonas metropolitanas en México", en Carlos Garrocho y Jaime Sobrino (coords.), Sistemas metropolitanos: nuevos enfoques y perspectivas, Zinacantepec, El Colegio Mexiquense/SEDESOL, pp. 19-46.

Núñez, Leopoldo (1992), "Estimates of infant mortality for the northern border of México", en John R. Weeks y Roberto Ham Chande (comps.), Demographic Dynamics of the U. S. Mexican Border, El Paso, University of Texas, pp. 151-163.

Ordorica Mellado, Manuel (1982), "Factores determinantes de la mortalidad", en Memoria sobre la Segunda Reunión Naciona sobre Investigación Demográfica en México, México, CONACYT, pp. 29-31.

Romero Montilla, Dalia Elena (1994), “Madres con más de un hijo fallecido en la infancia", en Memorias de la $I V$ Reunión Nacional de Investigación Demográfica en México, tomo 1, México, INEGI/SOMEDE, pp. 192-204.

Rodríguez Hernández, Francisco (1994), Condiciones de vida en e Estado de México: evolución en la década de los ochenta, Zinacantepec, El Colegio Mexiquense (Investigaciones 6).

Secretaría de Salud/DGPF/DHS (1988), Encuesta Nacional sobre Fecundidad y Salud, 1987, México, Dirección General de Planificación Familiar.

Sobrino, Luis Jaime (1994a), "Desempeño industrial del Estado de México en la década de los ochenta ${ }^{\mathrm{n}}$, en Roberto Blancarte (coord.), Estado de México: perspectivas para la década de los 90, Zinacantepec, El Colegio Mexiquense/Instituto Mexiquense de Cultura, pp. 337-364.

(1994b), "Proceso de metropolización en el Estado de México", en Emma Liliana Navarrete y Marta G. Vera Bolaños (coords.), Población y sociedad, Zinacantepec, El Colegio Mexiquense/Consejo Estatal de Población, pp. 179198.

United Nations (1990), Step by Step Guide to the Estimation d Child Mortality, Nueva York, United Nations Publication, ST/ESA/SER.A/107. 